\title{
Microbicides: Topical Prevention against HIV
}

\author{
Robin J. Shattock ${ }^{1}$ and Zeda Rosenberg ${ }^{2}$ \\ ${ }^{1}$ Centre for Infection and Immunity, Division of Clinical Sciences, St George's, University of London, \\ London SW17 ORE, United Kingdom \\ ${ }^{2}$ International Partnership for Microbicides, Silver Spring, Maryland 20910 \\ Correspondence: shattock@sgul.ac.uk
}

\begin{abstract}
Microbicides represent a potential intervention strategy for preventing HIV transmission. Vaginal microbicides would meet the need for a discreet method that women could use to protect themselves against HIV. Although early-generation microbicides failed to demonstrate efficacy, newer candidates are based on more potent antiretroviral (ARV) products. Positive data from the CAPRISA 004 trial of tenofovir gel support use in women and represent a turning point for the field. This article reviews current progress in development of ARVbased microbicides. We discuss the consensus on selection criteria, the potential for drug resistance, rationale for drug combinations, and the use of pharmacokinetic (PK)/pharmacodynamic (PD) assessment in product development. The urgent need for continued progress in development of formulations for sustained delivery is emphasized. Finally, as the boundaries between different prevention technologies become increasingly blurred, consideration is given to the potential synergy of diverse approaches across the prevention landscape.
\end{abstract}

\begin{abstract}
$A$ effective microbicide may be one of the Abest ways to address a central gap in current HIV prevention strategies: lack of a discreet method that women can use to protect themselves from infection. Recently, the World Health Organization reported that AIDS is the leading cause of death among women of reproductive age globally, and particularly in sub-Saharan Africa (World Health Organization 2009). Methods available to prevent HIV include condoms, male circumcision, and behavioral interventions, but data indicate that they are insufficient to protect women. Among women in sub-Saharan Africa, one of the highest-risk factors for acquiring HIV is being
\end{abstract}

in a stable long-term relationship where condom use is low (Shattock and Solomon 2004).

Condoms are impractical for women who want to conceive children or who cannot persuade their partners to use them. Next to an effective vaccine, microbicides (topical preexposure prophylaxis [PrEP]) and oral PrEP have the greatest potential to provide women with protection they can control. Both could be configured to protect men and women from transmission of HIV during unprotected anal intercourse.

Microbicides are topical PrEP products, such as gels, capsules, tablets, films, and intravaginal rings (IVR). They are designed to be applied either around the time of coitus, used

Editors: Frederic D. Bushman, Gary J. Nabel, and Ronald Swanstrom

Additional Perspectives on HIV available at www.perspectivesinmedicine.org

Copyright (C) 2012 Cold Spring Harbor Laboratory Press; all rights reserved; doi: 10.1101/cshperspect.a007385

Cite this article as Cold Spring Harb Perspect Med 2012;4:a007385 
on a daily basis (gels and films), or to deliver product over a prolonged period of time (IVR). The premise is inhibition or blockade of the earliest steps in the infection process at the vaginal or rectal mucosa. Because microbicides are topical, higher local drug concentrations can be delivered to virally exposed surfaces without significant systemic exposure, thereby reducing the risk of long-term toxicity in healthy but at-risk individuals.

\section{GENERAL PRINCIPLES FOR PRIORITIZING MICROBICIDE DEVELOPMENT}

Characteristics important to microbicide development are:

- Safety: Microbicides are designed for use by healthy individuals and should not demonstrate any localized toxicity. Avoiding any potential impact on epithelial surfaces and natural innate barriers that might tip the balance in favor of infection is particularly important. Long-term systemic toxicity associated with frequency and duration of product is equally important. Impact on fertility and/or fetal abnormalities is a crucial consideration for women.

- Efficacy: Any product must have a significant degree of efficacy in real-world situations. The level of efficacy required for adoption of a microbicide into different national programs remains the subject of much debate. Controversy also continues about the level of protection necessary to avoid negatively impacting condom use or discouraging other safe sex practices.

- Cost: A microbicide must be affordable to at-risk populations. Biological interventions may be effective, but if they are too expensive for mass distribution, they will never achieve widespread use.

- Acceptability: A microbicide must be acceptable for use in conjunction with sex. A product that demonstrates efficacy in a clinical trial with ongoing adherence counseling may be less acceptable in the real world and may not be adopted by at-risk populations.
- Appropriate drug delivery: For any microbicide to be effective, sufficient drug levels must be maintained in the appropriate compartments of the genital tract or rectum during exposure to virus. This feature has different implications for coitally dependent products than for those designed for sustained delivery.

- Long-term efficacy: As the field moves toward use of ARVs, the potential circulation within a given community of viruses resistant to the drug or drugs contained in a microbicide must be considered.

- Potential for resistance and impact on therapy: As ARV drugs used in treatment are increasingly included in microbicides, it will be important to ensure that their use for prevention does not induce drug resistance that might limit therapeutic options for individuals who become infected during product use.

- Prioritization of best-in-class products: It is not feasible to test every promising ARVbased microbicide in large clinical efficacy trials. Best-in-class products must be prioritized to maximize progress and prevent duplication. Prioritization should include in vitro activity ( potency and breadth), stage of product development (including manufacturing processes), stability under diverse environmental conditions in multiple topical dosage forms, and positive prior clinical experience.

\section{THE EARLY HISTORY OF MICROBICIDE DEVELOPMENT}

Microbicides were originally conceived as products that could offer broad protection against all or most sexually transmitted infections. The expectation was that they could be generated using simple nondrug-based compounds and could be provided over the counter (OTC) without a prescription.

Initial approaches focused on identification of existing OTC products with antiviral activity and were encouraged by early observations that surfactant-containing spermicides could disrupt the integrity of HIV in vitro 
(Malkovsky et al. 1988). Based on the potential for rapid introduction of existing products with in vitro activity against HIV, a large Phase III trial was performed using an OTC nonoxynol 9 spermicide, COL-1492 (Van Damme et al. 2002). It quickly became apparent, however, that surfactant-based products were insufficient to prevent HIV infection and also perturbed protective epithelial barriers when used frequently, potentially leading to higher rates of infection (Hillier et al. 2005). This early setback led to discontinuation of other strategies using surfactant-based products. An alternative approach was proposed, based on the observation that low $\mathrm{pH}(<4.5)$ could inactivate HIV (O'Connor et al. 1995). Based on these observations, it was hypothesized that acidbuffering gels could be used to lower vaginal $\mathrm{pH}$ and inactivate HIV (Mayer et al. 2001). Although shown to be safe in clinical trials, this is not sufficiently potent to prevent infection (Ramjee et al. 2010).

Researchers also discovered that long chain polyanionic compounds could prevent HIV infection in vitro. These compounds prevented HIV entry into target cells in vitro through nonspecific inhibition of viral binding to target cells (Fletcher and Shattock 2008). However, a range of polyanionic gels failed to show significant efficacy against HIV in clinical trials (Ramjee et al. 2010). Although a number of reasons for their lack of efficacy have been proposed, most researchers recognize they had insufficient potency. Disappointing results brought to a close this early chapter of microbicide development, opening a new phase of development focused on use of potent HIV-specific ARV drugs that interdict key stages in HIV replication: viral entry, reverse transcription, integration, and maturation.

\section{MATCHING MICROBICIDES TO MECHANISMS OF TRANSMISSION}

HIV transmission is relatively infrequent when considering the risk of infection per coital act (Dosekun and Fox 2010). However, risk of infection can be greatly influenced by the infectiousness of a sexual partner and the susceptibility of the exposed individual (Dosekun and Fox 2010). Recent genetic studies indicate that HIV infection is established by a single isolate in most women $(>80 \%)$ infected by the vaginal route (Keele et al. 2008; SalazarGonzalez et al. 2009; Keele 2010). The balance between exposure and successful or nonsuccessful infection is likely to be relatively small. Therefore, anything that can reduce the infectious dose during any exposure and/or increase an exposed individual's resistance to infection may have a significant impact on transmission rates. Likewise, the balance could be tipped in favor of infection if the normal flora are disturbed, innate protective factors are reduced, or protective epithelium is damaged or inflamed (Haase 2011).

\section{ARV DRUGS TO PREVENT INITIAL EVENTS IN MUCOSAL TRANSMISSION}

As noted above, current microbicide development is focused on the use of ARVs that interdict key stages in HIV replication: viral entry, reverse transcription, integration, and maturation (Fig. 1A). Viral entry into target cells represents the first point at which microbicides could interrupt initial transmission events (Fig. 1B). Although much is known about the viral life cycle, far less is known about initial events in the mucosa of the genital tract and rectum that must be prevented or aborted to ensure protection from HIV infection (Fig. 2). Microbicides have a relatively short window of opportunity for blocking infection. Increasing evidence from animal models suggests that infection is established relatively quickly at the mucosa after exposure to HIV. In a nonhuman primate (NHP) model, a 30 - to 60-min exposure to an infectious inoculum is sufficient to establish infection (Shattock and Moore 2003). That is most likely the time frame required for viral attachment to target cells and the optimal window for prevention of initial infection by entry inhibitors. Transmitted/ founder viruses recently have been found to primarily target CD4 central and effector memory populations within mucosal tissue, which express high levels of CCR5. Transmitted 
R.J. Shattock and Z. Rosenberg

A

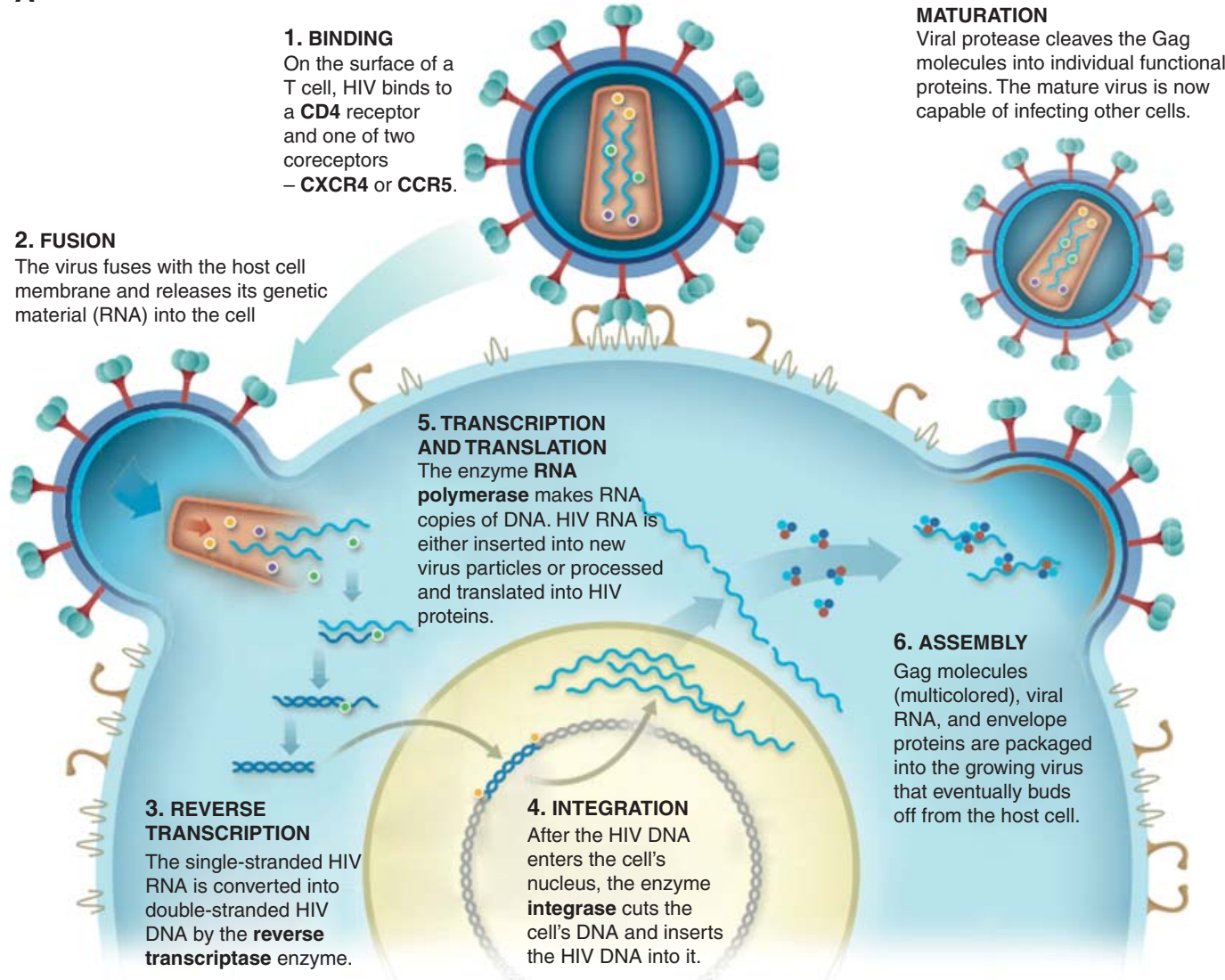

Figure 1. ARV drugs targeting the viral life cycle of HIV. (A) HIV entry is dependent on binding to its principle receptor, $\mathrm{CD} 4$, which triggers conformational change in the viral envelope (gp120) and subsequent engagement with one or two possible coreceptors (CCR5 or CXCR4), triggering subsequent fusion between the viral and cellular membranes. In most cases, virus using the CCR5 coreceptor (R5 virus) is the predominant strain mediating initial infection. Coreceptor engagement, in turn, causes conformational changes in gp 41 , leading to insertion of the fusion peptide into the cell membrane. Following membrane fusion, the viral core enters the cytoplasm of target cells and the process of reverse transcription begins. Following reverse transcription and generation of full-length double stranded proviral DNA, the viral enzyme integrase ensures provirus incorporation into the host cell DNA. Once incorporated into a target cell, the proviral DNA will persist for the lifetime of that cell and any potential progeny. Activation of host transcription factors known to bind to the long terminal repeat of the HIV genome initiates viral replication, which leads to assembly and budding of new virus. As part of this process, the viral enzyme protease cleaves two precursor viral polyproteins (Pr55 and Pr160), generating respective functional proteins essential for the maturation required to generate infectious virions. (B) Viral entry into target cells represents the first point at which microbicides could interrupt initial transmission events either binding to the viral envelope or blocking interaction with CD4 or coreceptor. Reverse transcription represents the second point at which a microbicide could potentially intervene through the activity of nucleoside/nucleotide reverse transcriptase inhibitors (NRTIs) or nonnucleotide reverse transcriptase inhibitors (NNRTIs). Integration, a third point of drug intervention, can be prevented by integrase inhibitors. Finally, protease inhibitors can block viral maturation leading to the release of defective noninfectious virions. (Continued on next page.) 


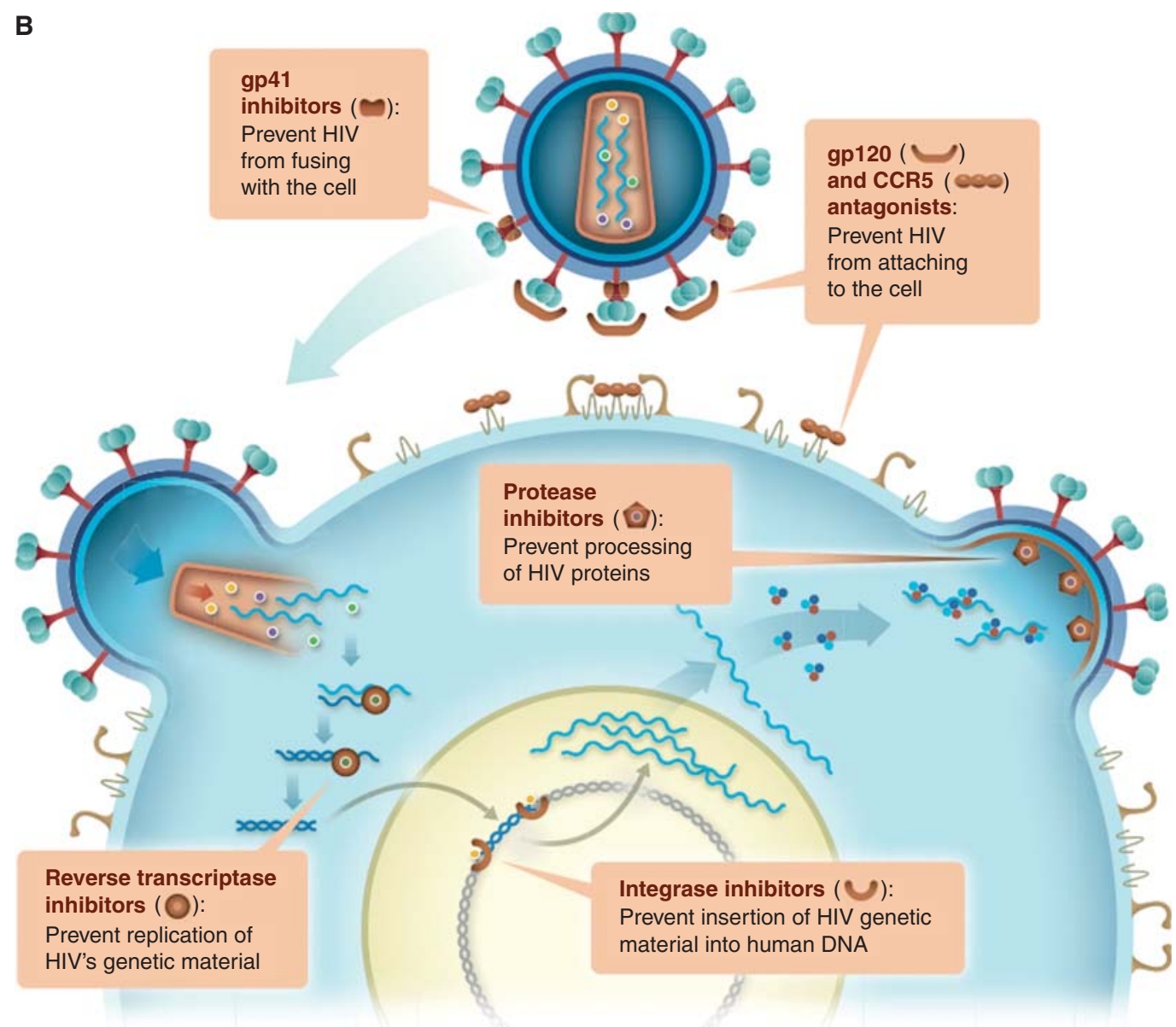

Figure 1. Continued

founder viruses appear to show low macrophage tropism, suggesting that infection of antigen-presenting cells may not be critical to establishment of an initial infection (SalazarGonzalez et al. 2009).

Tracking of labeled viruses in explant models and NHP studies has shown that the virus can penetrate superficial layers of stratified epithelium and come in contact with potentially susceptible $\mathrm{T}$ cells and Langerhans cells within these epithelial surfaces (Haase 2011). In NHP studies, infection has often been associated with areas of disruption in epithelial integrity and where stromal papillae are nearest to the tissue surface, providing the greatest chance of interaction with target cells (Haase 2011). The columnar epithelium in the endocervix and the rectum remains an important potential site of infection and may be more susceptible to damage because they are only a single cell deep.

Detailed studies in NHPs show that infection is established rapidly $(16-72 \mathrm{~h})$ within local mucosal tissue, forming an initial foci of infection (Haase 2011). Reverse transcriptase and integrase inhibitors that target preintegration steps in the viral lifecycle may readily prevent establishment of such foci. In order for infection to take hold, local propagation of virus requires the influx of additional activated CD4 cells (Haase 2011). Local expansion of these infected cells is thought to produce new 
R.J. Shattock and Z. Rosenberg
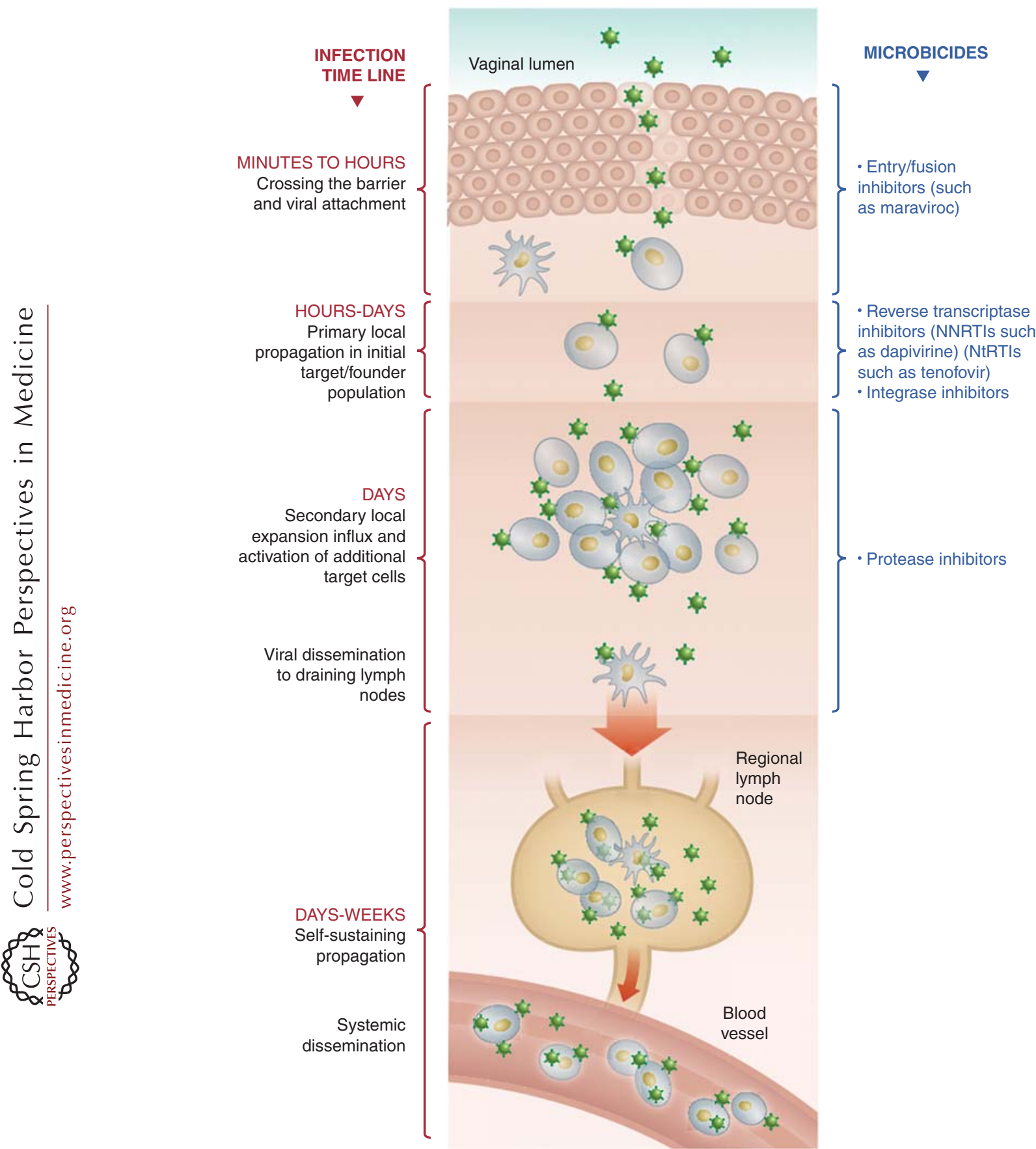

Figure 2. Initial events in mucosal infection and the potential points for microbicide intervention. 
virus sufficient for dissemination into draining lymph nodes, where infected cells can be detected within 24-72 h of exposure (Haase 2011). This local expansion is thought to be critical to establishing productive infection, and blockade of this step may abort an infection. Here, local expansion of an infected founder population might be inhibited by protease inhibitors able to prevent production of virus from the initial foci of infection. Virus dissemination to draining lymph nodes leads to self-sustaining propagation and latent reservoirs refractory to topical microbicides. Systemic dissemination then occurs in the days to weeks following initial exposure (Haase 2011).

Success with microbicides requires delivery of appropriate drugs to these target sites. Therefore, drugs need to be formulated and chosen with an understanding about PK following topical application. Likewise, drugs being used for oral PrEP need to be chosen and evaluated to ensure adequate penetration into the mucosal portals of entry so that sufficient drug is at the right place at the right time. Formulation considerations are discussed in more detail below.

\section{TARGETING OF VIRAL ENTRY}

Because binding of viral gp120 to CD4 is essential for productive infection, targeting this step likely would significantly impact infection. Drugs that can effectively block gp120-CD4 interaction, however, are few and, to date, none of those identified has been evaluated in humans as microbicides. One compound, cyclotriazadisulfonamide CADA, has been shown to down-regulate CD4 expression. If it proves safe, CADA may represent an interesting new strategy (Vermeire et al. 2008). Because CD4 is known to have important functional characteristics in driving $\mathrm{T}$ cell responses, the impact of sustained suppression on immunity is unknown. An alternative approach would be to target gp120 and prevent either its interaction with CD4 or subsequent downstream conformational change. A small protein mimic of CD4 has been identified and is known to effectively block HIV infection in vitro (Van
Herrewege et al. 2008). Manufacture and scale up of such an approach, however, represents a significant hurdle. An alternative approach is a family of small-molecule drugs known to bind to gp120 and prevent subsequent conformational change. This includes BMS-806, which has been shown to inhibit infection in vitro and prevent infection of NHPs ( $\mathrm{Si}$ et al. 2004; Veazey et al. 2005). A derivative of BMS-806, DS003, with a similar mechanism of action has been put into formal microbicide development. Both compounds are likely to bind to gp120 and prevent CD4 from inducing structural changes in gp 120 that drive the fusion protein gp41 to form six helix bundles and cause viral and cellular membranes to fuse ( $\mathrm{Si}$ et al. 2004). A parallel approach is use of synthetic peptides based on the gp41 sequence, which can bind to gp41 trimers and prevent formation of the six-helix bundle configuration necessary for juxtaposition of the viral and cellular membranes (Fig. 1B) (Shattock and Moore 2003). Two of these peptides-C52L and T1249have been shown to protect Rhesus macaques from SHIV challenge (Si et al. 2004; Veazey et al. 2008). This approach is biologically plausible but peptides are expensive and creating formulations that are stable in a mucosal environment remains challenging.

\section{INHIBITING CORECEPTOR INTERACTION}

In contrast to the approaches above, targeting coreceptors currently is the most plausible strategy for preventing viral fusion. HIV uses two principal coreceptors for fusion in vivo: CXCR4 and CCR5. Epidemiological evidence shows that virus using CCR5 (known as R5 virus) are responsible for $>90 \%$ of infections worldwide. Therefore, targeting CCR5 is a highly plausible intervention strategy. Drugs that target CCR5 include RANTES protein analogs (Lederman et al. 2004; Gaertner et al. 2008), and small module inhibitors such as CMPD167 (Veazey et al. 2005) and maraviroc (Veazey et al. 2010). Several CCR5 antagonists have been shown to protect against vaginal SHIV challenge in NHP studies (Lederman et al. 2004; Veazey et al. 2005, 2010). Maraviroc 
R.J. Shattock and Z. Rosenberg

is the only CCR5 inhibitor shown to be safe and effective in humans when used as a therapeutic drug. CCR5 antagonists, and specifically maraviroc, are thought to bind to the transmembrane domains of CCR5 and modify the conformation of its extracellular domains, thereby inhibiting gp120 binding to CCR5 (Fig. 3) (Kondru et al. 2008; Hu et al. 2010; Garcia-Perez et al. 2011). Recently, maraviroc also has been shown to prevent SHIV infection in NHP models when formulated as a microbicide (Veazey et al. 2010). Wide clinical experience and established manufacturing processes make maraviroc the most attractive candidate for microbicide development in this class of compounds.

\section{TARGETING REVERSE TRANSCRIPTASE}

\section{NRTIs}

Reverse transcriptase inhibitors and, in particular, nucleoside reverse transcriptase inhibitors (NRTIs) were the first class of drugs developed for HIV therapy (Broder 2010). They were also shown to have utility in postexposure prophylaxis and in prevention of mother-to-child transmission (PMTCT) (Wiznia et al. 1996). NRTIs block reverse transcription by competing with the natural nucleoside counterparts for incorporation into newly forming HIV DNA. Once successfully incorporated, termination of the elongating DNA chain ensues, and DNA synthesis is interrupted (Fig. 4). NRTIs'

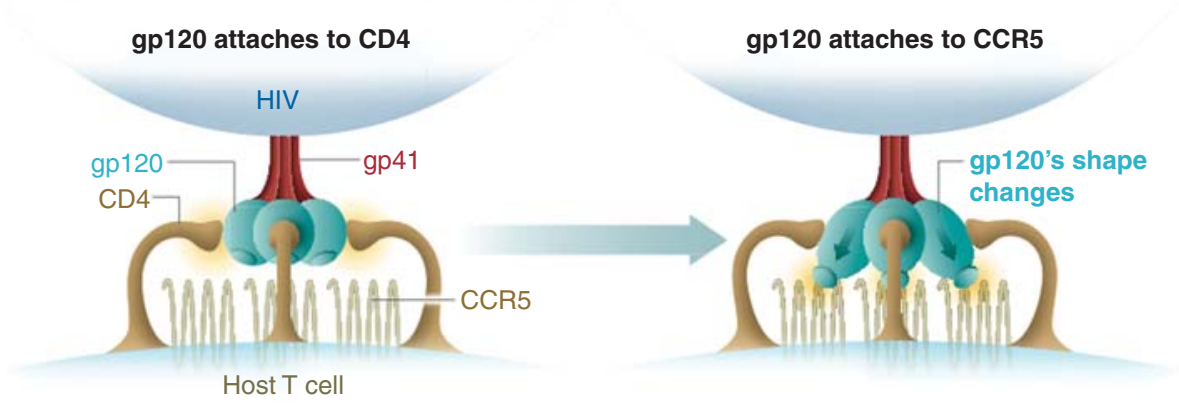

1. HIV ATTACHMENT

The HIV life cycle begins when a protein on the virus - gp120 - binds to a CD4 receptor on the cell. This in turn induces conformational change in gp120, facilitating its binding to a CCR5 or CXCR4 coreceptor and triggering viral fusion with the cell.

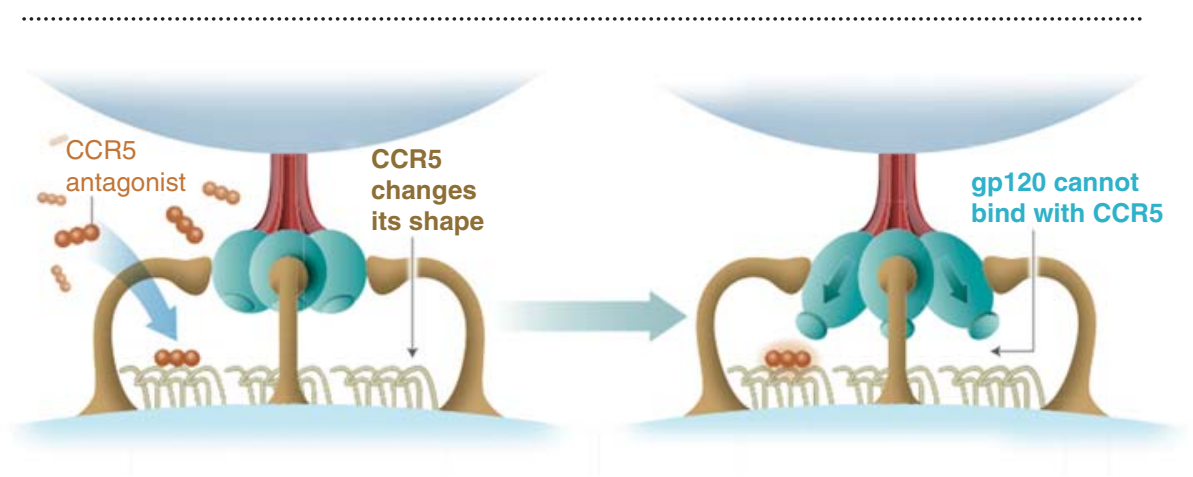

\section{CCR5 ANTAGONISTS}

CCR5 antagonists like maraviroc change the shape of CCR5, making it impossible for gp120 to bind to the CCR5 receptor, thereby inhibiting HIV attachment.

Figure 3. How CCR5 antagonists like maraviroc work. 

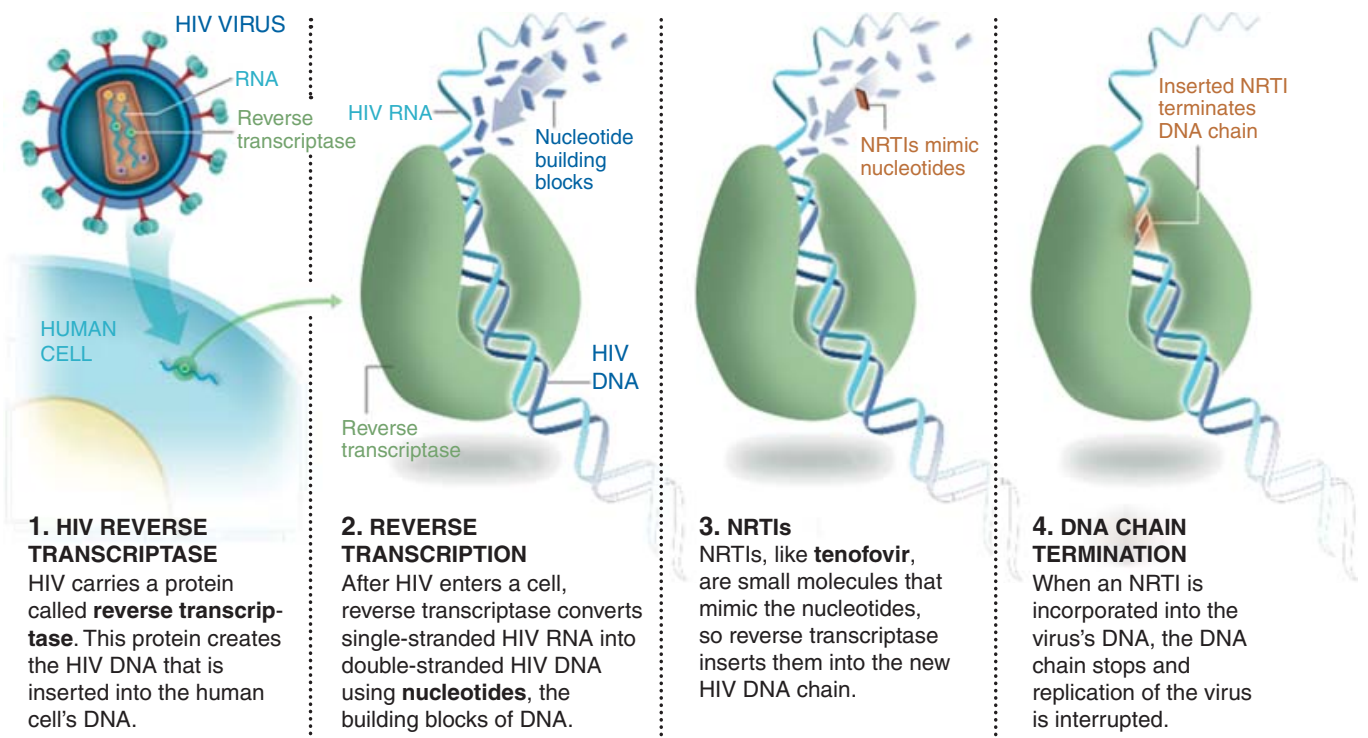

Figure 4. How NRTIs like tenofovir work.

potential use in microbicides was first demonstrated in a pivotal NHP vaginal challenge study in which $1 \%$ tenofovir gel was shown to prevent acquisition of SIV infection (Parikh et al. 2009). Given the promising data in macaques with NRTIs, tenofovir gel was evaluated for safety both preclinically and clinically, and a group of South African investigators carried out the first efficacy trial of an ARV-containing microbicide (Abdool Karim et al. 2010). The CAPRISA 004 trial demonstrated for the first time that an ARV-based microbicide could protect women from HIV infection. A number of interesting observations stemmed from this study. First, over a 36-month period, 1\% tenofovir gel was shown to provide a $39 \%$ reduction in HIV transmission. Interestingly, at 1 year, the figure was $50 \%$, and in those using the drug with $>80 \%$ compliance, it was shown to be 53\% effective (Abdool Karim et al. 2010).

Tenofovir has characteristics that may make it particularly suitable for use as a microbicide. It is the only licensed nucleotide RT inhibitor, which requires only two phosphorylations to become active, whereas nucleoside inhibitors such as AZT need three phosphorylations. More importantly, tenofovir has an extremely long tissue half-life, meaning that after the microbicide is applied, drug may remain active in tissue for prolonged periods (Rohan et al. 2010). This may provide a wider window of protection than other short-lived NRTIs, and in NHP studies, some protection was evident 3 days postapplication (Dobard et al. 2010), but the window remains to be determined in humans. Seven other NRTIs are licensed and already in use as therapeutic drugs and may be used in future combinations with tenofovir. Tenofovir + emtricitabine (FTC) has already shown activity in NHP studies and is in clinical development (Parikh et al. 2009).

\section{NNRTIs}

The second class of reverse transcriptase inhibitors is NNRTIs, drugs that are active through noncompetitive inhibition of the reverse transcriptase enzyme (Fig. 5). Several NNRTIs are widely used in treatment. Nevirapine has been used for PMTCT, providing biological plausibility for its use in prevention (Chasela et al. 2010). NNRTIs that have undergone preclinical evaluation as microbicides are dapivirine, UC781, MIV-150, and MC1220 (Fletcher et al. 2005; Fernandez-Romero et al. 2007; Fletcher and Shattock 2008; Caron et al. 2010). All of 
R.J. Shattock and Z. Rosenberg

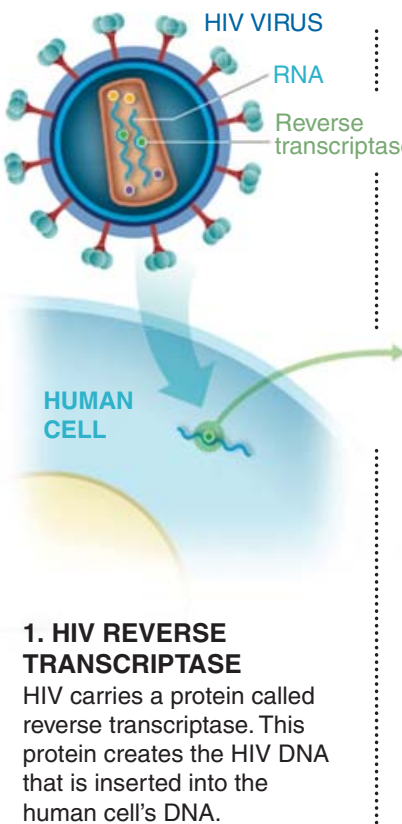

human cell's DNA.

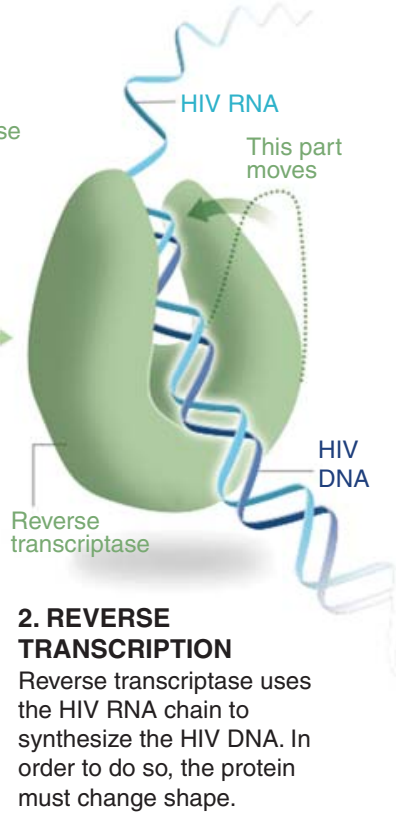

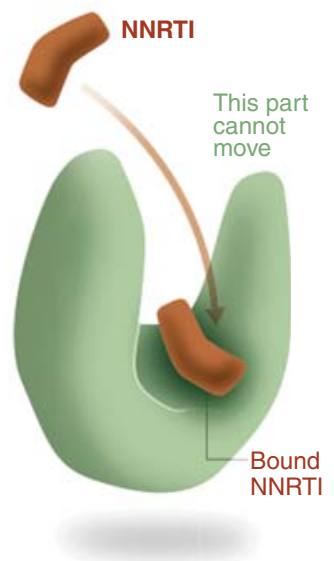

\section{NNRTI BINDING}

NNRTIs attach to reverse transcriptase, making it impossible for the protein to bind to HIV RNA, thereby preventing the creation of HIV DNA.

Figure 5. How NNRTIs like dapivirine work.

these drugs are known to show an extremely high-level affinity for binding to the RTenzyme; MIV-150 and MC1220 have been shown to prevent infection in NHP studies after vaginal challenge (Crostarosa et al. 2009; Caron et al. 2010; Kenney et al. 2011). Dapivirine is the most advanced of these candidates in terms of clinical development. Its poor oral bioavailability could potentially provide an advantage as a microbicide because topical application can achieve high levels of localized concentration with minimal systemic exposure. This feature may be important when considering potential longterm safety and/or resistance, as will be discussed later. Dapivirine shows extremely high activity in a range of preclinical models (Fletcher et al. 2009) by inference; it has the potential to be active in preventing HIV transmission when delivered as a microbicide.

\section{TARGETING VIRAL INTEGRATION}

Raltegravir, the only integrase inhibitor currently in therapeutic use (Powderly 2010), is undergoing preclinical study for potential use as a microbicide. Little published data currently exist on its activity in relevant preclinical microbicide models, but inhibition of viral integration remains an important target for prevention of initial events essential for viral transmission. Indeed, one integrase inhibitor has been shown to prevent SHIV challenge in a pilot NHP study (Dobard et al. 2010). The microbicide field will continue to watch the development of integrase inhibitors and their potential use in microbicide strategies.

\section{TARGETING VIRAL MATURATION}

Ten licensed protease inhibitors currently are in use for therapy (De Clercq 2010). These drugs have the highest barrier to resistance when used for therapy and represent interesting potential candidates as microbicides. Whether drugs that block postintegration events would be able to prevent transmission remains unclear. However, infection of mucosal tissue is hypothesized to be initiated by a small foci of infected cells and establishment of infection is hypothesized to require virus dissemination after such initial events (Fig. 2) (Haase 2011). It is quite plausible that protease inhibitors 
may be able to block dissemination from any initial focus for a sufficient time before the localized infection is eliminated or dies through lack of onward spread. Protease inhibitors are being assessed for microbicide activity in preclinical in vitro models and NHP studies. Should they show promise, they likely will be used in future microbicide formulations, most probably in combination with other drugs.

\section{NEW RESEARCH AREAS}

\section{Development of Formulation Strategies}

The initial concept of a microbicide was based on coitally dependent application of a gel formulation (i.e., dosing close to each act of sexual intercourse). This mode of delivery remains an important strategy, as it may be preferable to many women. The advantage of this approach is that it provides a bolus of drug directly before potential viral exposure. The disadvantages are related to compliance. Women must be able to anticipate when they may have sex and be able to apply a product discreetly in advance. For many women in the developing world, this may be impractical, and it would be complicated by the need to ensure that a microbicide is always readily available and could still be reliably used if sex took place in the context of drugs, alcohol, or abuse. Experience indicates that it is often difficult to ensure compliance with coitally dependent microbicides in the context of clinical trials (Turner et al. 2009; Greene et al. 2010).

The timing of nevirapine in its proven strategy for preventing mother-to-child HIV transmission led the CAPRISA 004 team to design a clinical trial with the BAT-24 "before and after sex" dosing regimen (Abdool Karim et al. 2010). BAT-24 required administration of tenofovir gel any time in the 12 hours preceding intercourse and a second dose of gel in the 12 hours after intercourse for no more than two doses in any 24-h period (Fig. 6). This regimen was envisaged to be more flexible and to increase the chance of having two drug doses available around the time of transmission-one before and one after a sex act. BAT-24 with tenofovir gel was the first microbicide regimen to demonstrate protection from HIV. How critical each dose and the timing around sex were for optimal protection is unclear. Nevertheless, the results from CAPRISA 004 represent a significant step forward. A second trial with the BAT-24 dosing regimen is planned to begin in early 2011.

A third approach has been development of trials around daily dosing with tenofovir gel, as is currently being assessed in the VOICE trial by the Microbicide Trials Network (http:// www.mtnstopshiv.org/news/studies/mtn003/ backgrounder). With this regimen, subjects are asked to apply the product once a day independent of any sex acts. It is hoped that compliance with daily dosing would provide steady-state drug levels within the optimal dosing concentration required for protection (Fig. 6). This approach is anticipated to lead to greater compliance because it can be incorporated as a routine act in daily life.

A fourth approach is sustained drug delivery, which is designed around IVRs already being used to deliver hormone replacement therapy and hormonal contraception. Silicone elastomer-impregnated rings can release hydrophobic drugs for prolonged periods. Recent studies have shown that an IVR can deliver the NNRTI dapivirine under steady release conditions for a minimum of a month ( $\mathrm{Nel}$ et al. 2009; Malcolm et al. 2010). Studies in Africa have shown that such rings are highly acceptable in at-risk populations (Smith et al. 2008; Woodsong et al. 2010). The advantage of an IVR is that it can be worn safely for a month or longer. The premise is that IVRs can deliver optimal concentrations of drug required for protection (Fig. 6). However, one of the tradeoffs against the benefits of an IVR is that it may not release drug at levels equal to what is achievable with daily or coitally related dosing with gels, films, etc. Nevertheless, compliance with the ring may be higher because there is no requirement to plan for each sexual act or to use the product on a daily basis.

Ultimately, development of multiple formulations would give women the choice of an approach that best fits their circumstances. 


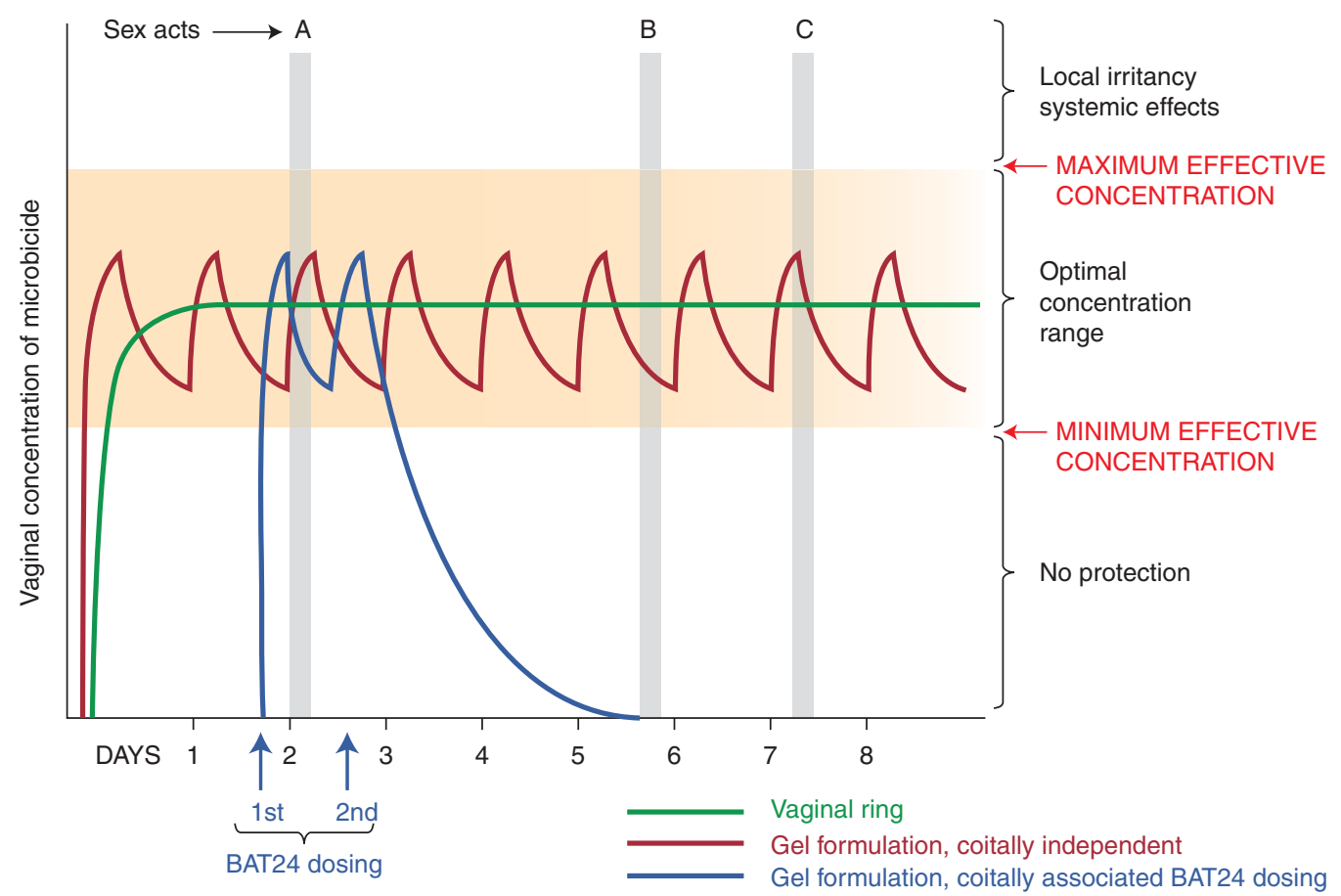

Figure 6. Microbicide dosing schemes: coitally dependent and independent.

Ongoing efforts to increase the range of formulations include development of rapid-dissolving vaginal tablets and small dissolvable films for vaginal application (Romano et al. 2008). Once a drug candidate has shown efficacy in clinical trials, other formulations of the same product may be evaluated to provide greater choice to women.

\section{PHARMACOKINETICS (PK) AND PHARMACODYNAMICS (PD) IN CLINICAL ASSESSMENT}

Phase III clinical trials are expensive, timeconsuming, and require a large number of participants to determine efficacy. Such trials cost between \$50-\$100 million. Furthermore, as successive interventions are introduced, incidence of infection within communities will decrease and the window for performing placebo-controlled trials will close. This will mean that testing of later-generation products will become more complex because reduced incidence and provision of an increasing number of prevention options will require even larger trials. The move to ARV-based microbicides has meant that candidates can be assessed using traditional drug development tools, including PK (measurement of drug absorption, retention, and distribution over time) and in parallel PD (assessment of drug activity within biological compartments). These tools are becoming increasingly important in microbicide development to accelerate prioritization of candidates, combinations, and formulations prior to Phase III. Once the concentration required to provide protection within mucosal tissue is known, different formulations can be assessed against this potential biological parameter.

More recent efforts have also focused on establishment of potential PD markers. The basic principle is to take biopsies from mucosal tissue following drug application and determine whether the tissue is resistant to infection when challenged with live virus in the laboratory. In the first PD study of a rectal microbicide in humans, two different doses of the NNRTI 
UC781 and a placebo gel showed different PD properties. The highest dose tested was shown to significantly reduce viral replication in tissue biopsies challenged after drug application (Anton et al. 2009). This technology now is being applied to development of vaginal microbicides, which is more complex because only one to two biopsy samples can be taken from a woman's vagina, in contrast to the 10-30 biopsies that can safely be taken from the colon and rectum. It remains to be seen whether ex vivo challenge of single cervical biopsy from women postdosing with product would be sufficient to effectively assess microbicide PD. An alternative approach to establish a marker of PD has been the analysis of anti-HIV activity in cervical fluid following vaginal application of microbicide formulations (Keller et al. 2010; Herold et al. 2011). PK and PD are emerging tools that may be critical for rapid assessment and introduction of new formulations of a product once it has shown efficacy in a clinical trial. Furthermore, these studies may be important in assessing ongoing drug combinations designed to increase the efficacy of products once singleARV microbicides have been proven effective.

\section{RESISTANCE TO ARV MICROBICIDES}

When ARV-based microbicides are introduced, the potential impact on current and future therapeutic strategies must be considered. This consequence is particularly important because many drugs used as microbicides are components of products already in use for front-line and second-line treatment. The long-term implications would be serious if a microbicide significantly reduced treatment because it induced resistance. Such concerns are not without precedence, as treatment with nevirapine for PMTCT has been associated with induction of resistance to that drug, although the impact on subsequent therapy remains controversial (Lockman et al. 2010; Palumbo et al. 2010). The potential for resistance following topical use of a drug that does not deliver significant systemic levels, however, remains theoretical and can only be tested in a clinical setting (IPM 2008; Wilson et al. 2008). Interestingly, no evidence of resistance to tenofovir was seen in women in CAPRISA 004 who became infected during the trial. It remains unclear, however, how compliant with the BAT 24 regimen the subjects who became infected were and, therefore, what impact the dosing frequency had on induction of resistance.

Resistance can occur under two potential scenarios. The first is transmission of resistant isolates. In any community where treatment is widespread, resistant isolates will exist. An individual using a microbicide based on a single ARV potentially would be susceptible to transmission of such a resistant isolate because it might not be blocked by the drug to which it is resistant. It should be noted, however, that resistance generally is relative and not absolute. Therefore, viruses resistant to an individual drug can still be inhibited if the drug is applied in sufficient concentration. The advantage of topical dosing with ARVs is that they can be safely applied at concentrations many times higher than can be achieved with oral delivery. Whether resistant virus would survive the high concentrations within the mucosal environment is unclear. Nevertheless, that needs to be closely monitored.

The second scenario that could lead to resistance involves the continued use of an ARVbased microbicide by an individual following HIV infection. Here active replication within the individual could give rise to selection of resistance mutations to the drug contained in the microbicide. Again, the risk is theoretical and the likelihood is unknown. However, the resistance scenarios have led to the notion that ARV-based microbicides should not be available over the counter after they are licensed. Access to such products would require demonstration of seronegative status and potentially frequent monitoring to ensure that seroconversion has not occurred. If an individual using an ARV-based microbicide were to become infected, she or he immediately would be advised to stop using the product. This approach is being implemented in all clinical trials. How frequently individuals should be tested once a microbicide is licensed is unclear, but it is likely that monitoring for resistance will be done 
during Phase IV roll out of any ARV-based microbicide. If resistance becomes an issue, increased focus will be placed on development of combination microbicides aimed at limiting this risk.

\section{COMBINATION MICROBICIDES}

Development and efficacy testing of single-drug candidates is the current focus of microbicide clinical trials, and microbicide combinations are already being assessed as next-generation products. There are three principal reasons for combination-based microbicides. The first is to increase the breadth of activity. Any single ARV microbicide would be circumvented by a virus that is naturally resistant to the drug or exploits a mechanism that allows it to bypass the drug's activity. Second, ARV combinations may be additive or synergistic, thus allowing lower concentrations of drugs to have more potent activity against HIV. Third, combining drugs that interfere with different stages in the transmission process and the viral lifecycle would provide greater chances of protection. This is supported by the observed superiority of highly active ART in prevention of mother-child transmission (PMTCT) (Sturt et al. 2010).

Clinical trials to test microbicide drug combinations have their own challenges. Combination studies traditionally require testing individual drugs in separate arms against the combination. Here the emphasis is on demonstrating that the combination is more effective than either drug alone. Although safety and PK trials of combination microbicides are feasible, there may not be sufficient scope, funding, and/or subjects to provide continual iterations of drug combinations as microbicides are introduced. It is more likely that single-drug microbicides will be licensed initially, and that ongoing studies then will assess whether combining other drugs with these candidates can increase their potency. The first drugs to show efficacy in clinical trials likely will dominate subsequent microbicide drug development, with combinations focused on the first licensed products. Innovative strategies to bridge from $\mathrm{PK} / \mathrm{PD}$ to efficacy will be needed to ensure that optimal microbicide combinations are available.

\section{MICROBICIDES IN THE CONTEXT OF OTHER PREVENTION TECHNOLOGIES}

Early models of the impact of an effective microbicide on transmission rates anticipate that it would be bi-directional, that is, preventing infection from men to women and from women to men (Watts et al. 2002). Whether ARV-based microbicides would directly reduce transmission from women to men is unclear. Nevertheless, reducing the incidence of infection in women would, by implication, reduce the number of women who could transmit HIV to additional male partners.

Concern has been raised that microbicides might lead to reduced use of condoms. Models of the impact of microbicide introduction, based on different levels of efficacy and the potential impact of such a strategy on current condom use, suggest that the effects are likely to be small if a microbicide is $>50 \%$ effective and consistent condom use in the population is $<70 \%$ (Foss et al. 2003). Recent results from the iPrEX trial of oral PrEP showed 44\% (MIT) efficacy overall and up to $50 \%$ efficacy in participants who were $>50 \%$ compliant (Grant et al. 2010). It is unclear whether combining oral PrEP with microbicide might provide even higher levels of protection.

The major challenge for PrEP with both oral agents and topical microbicides will be the ongoing issue of compliance. Individuals are often poor judges of potential risk when it comes to different partners. This means that if a microbicide is used intermittently based on perception of risk, rather than routinely, then exposure is likely to occur in the absence of a microbicide. In that scenario, combining PrEP (topical or oral) with a suboptimal vaccine could have potential. Recent data from the RV-144 vaccine trial in Thailand suggest that vaccine candidates may be successful in low-risk cohorts (Rerks-Ngarm et al. 2009). Microbicide use could turn high-risk cohorts into low-risk cohorts in which superimposition of a suboptimal vaccine could further reduce transmission 
rates (Excler et al. 2010). The potential exists for use of microbicides in the context of a vaccine, but assessing potential synergies between the two approaches is a significant challenge for clinical trial design (Excler et al. 2010).

\section{CONCLUSIONS}

With the adoption of highly active ARV-based products for development, the microbicide field has benefitted from a highly successful therapeutic field. Partnerships between pharmaceutical companies and public-private partnerships, together with support from government agencies, have resulted in accelerated development of ARV-based microbicides. Researchers are optimistic that efficacy of microbicides can be increased through different dosing regimens and formulation strategies. The groundbreaking results from the CAPRISA 004 trial show that microbicides can be effective.

A number of Phase III trials of microbicides are currently underway or about to be initiated, including research on tenofovir gel and a dapivirine IVR. The challenge is to build on such early proof-of-concept, and develop approaches that are even more effective, together with a wider range of products that provide women with optimal choice in HIV prevention. It is our fervent hope that in the near future microbicides are introduced as part of a comprehensive, multicomponent prevention strategy that continues to evolve as additional options become available.

\section{ACKNOWLEDGMENTS}

We greatly acknowledge the editorial help of Pamela N. Norick, Judy Orvos, and Sarah Harman. Illustrations were produced by $5 \mathrm{~W}$ Infographics based on original diagrams from the authors. Z.F.R. is the Chief Executive Officer of the International Partnership for Microbicides.

\section{REFERENCES}

Abdool Karim Q, Abdool Karim SS, Frohlich JA, Grobler AC, Baxter C, Mansoor LE, Kharsany AB, Sibeko S, Mlisana KP, Omar Z, et al. 2010. Effectiveness and safety of tenofovir gel, an antiretroviral microbicide, for the prevention of HIV infection in women. Science 329: $1168-1174$.

Anton P, Tanner K, Cho D, Johnson E, Cumberland B, Zhou Y, Mauck C, McGowan I. 2009. Strong suppression of HIV-1 infection of colorectal explants following in vivo rectal application of UC781 gel: A novel endpoint in a phase 1 trial. In 16th Conference on Retroviruses and Opportunistic Infections. Montreal, Canada.

Broder S. 2010. Twenty-five years of translational medicine in antiretroviral therapy: Promises to keep. Sci Transl Med 2: 39ps33.

Caron M, Besson G, Etenna SL, Mintsa-Ndong A, Mourtas S, Radaelli A, Morghen Cde G, Loddo R, La Colla P, Antimisiaris SG, et al. 2010. Protective properties of non-nucleoside reverse transcriptase inhibitor (MC1220) incorporated into liposome against intravaginal challenge of Rhesus macaques with RT-SHIV. Virology 405: 225-233.

Chasela CS, Hudgens MG, Jamieson DJ, Kayira D, Hosseinipour MC, Kourtis AP, Martinson F, Tegha G, Knight RJ, Ahmed YI, et al. 2010. Maternal or infant antiretroviral drugs to reduce HIV-1 transmission. N Engl J Med 362: 2271-2281.

Crostarosa F, Aravantinou M, Akpogheneta OJ, Jasny E, Shaw A, Kenney J, Piatak M, Lifson JD, Teitelbaum A, $\mathrm{Hu} \mathrm{L}$, et al. 2009. A macaque model to study vaginal HSV-2/immunodeficiency virus co-infection and the impact of HSV-2 on microbicide efficacy. PLoS One 4: e8060.

De Clercq E. 2010. Antiretroviral drugs. Curr Opin Pharmacol 10: 507-515.

Dobard C, Sharma S, Holder A, Kuklenyik Z, Hanson D, Smith J, Otten RA, Novembre FJ, Garcia-Lermal G, Heneine W. 2010a. Protection by TFV gel against vaginal SHIV infection in macaques three days after gel application and its relationship to tissue drug levels. In Microbicides 2010. Pittsburgh.

Dobard CW, Sharma S, Martin A, Hazuda D, Hanson D, Smith J, Otten RA, Novembre F, Garcia-Lerma G, Heneine W. 2010b. Protection against repeated vaginal SHIV exposures in macaques by a topical gel with an integrase inhibitor. In Microbicides 2010. Pittsburgh.

Dosekun O, Fox J. 2010. An overview of the relative risks of different sexual behaviours on HIV transmission. Curr Opin HIVAIDS 5: 291-297.

Excler JL, Rida W, Priddy F, Gilmour J, McDermott AB, Kamali A, Anzala O, Mutua G, Sanders EJ, Koff W, et al. 2010. AIDS vaccines and preexposure prophylaxis: Is synergy possible? AIDS Res Hum Retrov doi: 101089/ aid20100206.

Fernández-Romero JA, Thorn M, Turville SG, Titchen K, Sudol K, Li J, Miller T, Robbiani M, Maguire RA, Buckheit RW Jr, et al. 2007. Carrageenan/MIV-150 (PC-815), a combination microbicide. Sex Transm Dis 34: 9-14.

Fletcher PS, Shattock RJ. 2008. PRO-2000, an antimicrobial gel for the potential prevention of HIV infection. Curr Opin Invest Drugs 9: 189-200.

Fletcher P, Kiselyeva Y, Wallace G, Romano J, Griffin G, Margolis L, Shattock R. 2005. The nonnucleoside reverse transcriptase inhibitor UC-781 inhibits human immunodeficiency virus type 1 infection of human cervical 
tissue and dissemination by migratory cells. J Virol 79: 11179-11186.

Fletcher P, Harman S, Azijn H, Armanasco N, Manlow P, Perumal D, de Bethune MP, Nuttall J, Romano J, Shattock R. 2009. Inhibition of human immunodeficiency virus type 1 infection by the candidate microbicide dapivirine, a nonnucleoside reverse transcriptase inhibitor. Antimicrob Agents Chemother 53: 487-495.

Foss AM, Vickerman PT, Heise L, Watts CH. 2003. Shifts in condom use following microbicide introduction: Should we be concerned? AIDS 17: 1227-1237.

Gaertner H, Cerini F, Escola JM, Kuenzi G, Melotti A, Offord R, Rossitto-Borlat I, Nedellec R, Salkowitz J, Gorochov G, et al. 2008. Highly potent, fully recombinant anti-HIV chemokines: Reengineering a low-cost microbicide. Proc Natl Acad Sci 105: 17706-17711.

Garcia-Perez J, Rueda P, Staropoli I, Kellenberger E, Alcami J, Arenzana-Seisdedos F, Lagane B. 2011. New insights into the mechanisms whereby low molecular weight CCR5 ligands inhibit HIV-1 infection. J Biol Chem 286: 4978-4990.

Grant RM, Lama JR, Anderson PL, McMahan V, Liu AY, Vargas L, Goicochea P, Casapía M, Guanira-Carranza JV, Ramirez-Cardich ME, et al. 2010. Preexposure chemoprophylaxis for HIV prevention in men who have sex with men. N Engl J Med 363: 2587-2599.

Greene E, Batona G, Hallad J, Johnson S, Neema S, Tolley EE. 2010. Acceptability and adherence of a candidate microbicide gel among high-risk women in Africa and India. Cult Health Sex 12: 739-754.

Haase AT. 2011. Early events in sexual transmission of HIV and SIV and opportunities for interventions. Annu Rev Med 62: 127-139.

Herold BC, Mesquita PM, Madan RP, Keller MJ. 2011. Female genital tract secretions and semen impact the development of microbicides for the prevention of HIV and other sexually transmitted infections. Am J Reprod Immunol 65: 325-333.

Hillier SL, Moench T, Shattock R, Black R, Reichelderfer P, Veronese F. 2005. In vitro and in vivo: The story of nonoxynol 9. J Acq Immune Def Synd 39: 1-8.

Hu Q, Huang X, Shattock RJ. 2010. C-C chemokine receptor type 5 (CCR5) utilization of transmitted and early founder human immunodeficiency virus type 1 envelopes and sensitivity to small-molecule CCR5 inhibitors. J Gen Virol 91: 2965-2973.

IPM. 2008. Consensus Statement by IPM and the Executive Committee of the IPM Scientific Advisory Board. The Use of Antiretroviral Drugs (ARVs) in Microbicides and the Potential for the Development of Drug-resistant Strains of HIV. http://www.ipmglobal.org/publicationsmedia/ipm-consensus-statement-resistance.

Keele BF. 2010. Identifying and characterizing recently transmitted viruses. Curr Opin HIVAIDS 5: 327-334.

Keele BF, Giorgi EE, Salazar-Gonzalez JF, Decker JM, Pham KT, Salazar MG, Sun C, Grayson T, Wang S, Li H, et al. 2008. Identification and characterization of transmitted and early founder virus envelopes in primary HIV-1 infection. Proc Natl Acad Sci 105: 7552-7557.

Keller MJ, Mesquita PM, Torres NM, Cho S, Shust G, Madan RP, Cohen HW, Petrie J, Ford T, Soto-Torres L, et al. 2010. Postcoital bioavailability and antiviral activity of $0.5 \%$
PRO 2000 gel: Implications for future microbicide clinical trials. PLoS One 5: e8781.

Kenney J, Aravantinou M, Singer R, Hsu M, Rodriguez A, Kizima L, Abraham CJ, Menon R, Seidor S, Chudolij A, et al. 2011. An antiretroviral/zinc combination gel provides 24 hours of complete protection against vaginal SHIV infection in macaques. PLoS One 6: e15835.

Kondru R, Zhang J, Ji C, Mirzadegan T, Rotstein D, Sankuratri S, Dioszegi M. 2008. Molecular interactions of CCR5 with major classes of small-molecule anti-HIV CCR5 antagonists. Mol Pharmacol 73: 789-800.

Lederman MM, Veazey RS, Offord R, Mosier DE, Dufour J, Mefford M, Piatak MJr, Lifson JD, Salkowitz JR, Rodriguez B, et al. 2004. Prevention of vaginal SHIV transmission in rhesus macaques through inhibition of CCR5. Science 306: 485-487.

Lockman S, Hughes MD, McIntyre J, Zheng Y, Chipato T, Conradie F, Sawe F, Asmelash A, Hosseinipour MC, Mohapi L, et al. 2010. Antiretroviral therapies in women after single-dose nevirapine exposure. N Engl J Med 363: 1499-1509.

Malcolm RK, Edwards KL, Kiser P, Romano J, Smith TJ. 2010. Advances in microbicide vaginal rings. Antiviral Res 88: S30-S39.

Malkovsky M, Newell A, Dalgleish AG. 1988. Inactivation of HIV by nonoxynol-9. Lancet 1: 645 .

Mayer KH, Peipert J, Fleming T, Fullem A, Moench T, Cu-Uvin S, Bentley M, Chesney M, Rosenberg Z. 2001. Safety and tolerability of BufferGel, a novel vaginal microbicide, in women in the United States. Clin Infect Dis 32: $476-482$.

Nel A, Smythe S, Young K, Malcolm K, McCoy C, Rosenberg Z, Romano J. 2009. Safety and pharmacokinetics of dapivirine delivery from matrix and reservoir intravaginal rings to HIV-negative women. J Acq Immune Def Synd 51: $416-423$.

O’Connor TJ, Kinchington D, Kangro HO, Jeffries DJ. 1995. The activity of candidate virucidal agents, low $\mathrm{pH}$ and genital secretions against HIV-1 in vitro. Int J STD AIDS 6: 267-272.

Palumbo P, Lindsey JC, Hughes MD, Cotton MF, Bobat R, Meyers T, Bwakura-Dangarembizi M, Chi BH, Musoke P, Kamthunzi P, et al. 2010. Antiretroviral treatment for children with peripartum nevirapine exposure. $N \mathrm{Engl} \mathrm{J}$ Med 363: 1510-1520.

Parikh UM, Dobard C, Sharma S, Cong ME, Jia H, Martin A, Pau CP, Hanson DL, Guenthner P, Smith J, et al. 2009. Complete protection from repeated vaginal simian-human immunodeficiency virus exposures in macaques by a topical gel containing tenofovir alone or with emtricitabine. J Virol 83: 10358-10365.

Powderly WG. 2010. Integrase inhibitors in the treatment of HIV-1 infection. J Antimicrob Chemother 65: 2485-2488.

Ramjee G, Kamali A, McCormack S. 2010. The last decade of microbicide clinical trials in Africa: From hypothesis to facts. AIDS 24: S40-S49.

Rerks-Ngarm S, Pitisuttithum P, Nitayaphan S, Kaewkungwal J, Chiu J, Paris R, Premsri N, Namwat C, de Souza M, Adams E, et al. 2009. Vaccination with ALVAC and AIDSVAX to prevent HIV-1 infection in Thailand. N Engl J Med 361: 2209-2220. 
Rohan LC, Moncla BJ, Kunjara Na Ayudhya RP, Cost M, Huang Y, Gai F, Billitto N, Lynam JD, Pryke K, Graebing P, et al. 2010. In vitro and ex vivo testing of tenofovir shows it is effective as an HIV-1 microbicide. PLoS One 5: e9310.

Romano J, Malcolm RK, Garg S, Rohan LC, Kaptur PE. 2008. Microbicide delivery: Formulation technologies and strategies. Curr Opin HIVAIDS 3: 558-566.

Salazar-Gonzalez JF, Salazar MG, Keele BF, Learn GH, Giorgi EE, Li H, Decker JM, Wang S, Baalwa J, Kraus $\mathrm{MH}$, et al. 2009. Genetic identity, biological phenotype, and evolutionary pathways of transmitted/founder viruses in acute and early HIV-1 infection. J Exp Med 206: $1273-1289$.

Shattock RJ, Moore JP. 2003. Inhibiting sexual transmission of HIV-1 infection. Nat Rev Microbiol 1: 25-34.

Shattock R, Solomon S. 2004. Microbicides-aids to safer sex. Lancet 363: 1002-1003.

Si Z, Madani N, Cox JM, Chruma JJ, Klein JC, Schön A Phan N, Wang L, Biorn AC, Cocklin S, et al. 2004. Smallmolecule inhibitors of HIV-1 entry block receptorinduced conformational changes in the viral envelope glycoproteins. Proc Natl Acad Sci 101: 5036-5041.

Smith DJ, Wakasiaka S, Hoang TD, Bwayo JJ, Del Rio C Priddy FH. 2008. An evaluation of intravaginal rings as a potential HIV prevention device in urban Kenya: Behaviors and attitudes that might influence uptake within a high-risk population. J Womens Health 17: 1025-1034.

Sturt AS, Dokubo EK, Sint TT. 2010. Antiretroviral therapy (ART) for treating HIV infection in ART-eligible pregnant women. Cochrane Database Syst Rev 3: CD008440.

Turner AN, De Kock AE, Meehan-Ritter A, Blanchard K, Sebola MH, Hoosen AA, Coetzee N, Ellertson C. 2009 Many vaginal microbicide trial participants acknowledged they had misreported sensitive sexual behavior in face-to-face interviews. J Clin Epidemiol 62: 759-765.

Van Damme L, Ramjee G, Alary M, Vuylsteke B, Chandeying V, Rees H, Sirivongrangson P, Mukenge-Tshibaka L, Ettiègne-Traoré V, Uaheowitchai C, et al. 2002. Effectiveness of COL-1492, a nonoxynol-9 vaginal gel, on HIV-1 transmission in female sex workers: A randomised controlled trial. Lancet 360: 971-977.
Microbicides: Topical Prevention against HIV

Van Herrewege Y, Morellato L, Descours A, Aerts L, Michiels J, Heyndrickx L, Martin L, Vanham G. 2008. CD4 mimetic miniproteins: Potent anti-HIV compounds with promising activity as microbicides. J Antimicrob Chemother 61: 818-826.

Veazey RS, Klasse PJ, Schader SM, Hu Q, Ketas TJ, Lu M, Marx PA, Dufour J, Colonno RJ, Shattock RJ, et al. 2005. Protection of macaques from vaginal SHIV challenge by vaginally delivered inhibitors of virus-cell fusion. Nature 438: 99-102.

Veazey RS, Ketas TA, Klasse PJ, Davison DK, Singletary M, Green LC, Greenberg ML, Moore JP. 2008. Tropismindependent protection of macaques against vaginal transmission of three SHIVs by the HIV-1 fusion inhibitor T-1249. Proc Natl Acad Sci 105: 10531-10536.

Veazey RS, Ketas TJ, Dufour J, Moroney-Rasmussen T, Green LC, Klasse PJ, Moore JP. 2010. Protection of rhesus macaques from vaginal infection by vaginally delivered maraviroc, an inhibitor of HIV-1 entry via the CCR5 co-receptor. J Infect Dis 202: 739-744.

Vermeire K, Brouwers J, Van Herrewege Y, Le Grand R, Vanham G, Augustijns P, Bell TW, Schols D. 2008. CADA, a potential anti-HIV microbicide that specifically targets the cellular CD4 receptor. Curr HIV Res 6: 246-256.

Watts C, Vickerman P, Terris-Prestholt F. 2002. The public health benefits of microbicides in lower-income countries. Rockefeller Foundation, New York.

Wilson DP, Coplan PM, Wainberg MA, Blower SM. 2008. The paradoxical effects of using antiretroviral-based microbicides to control HIV epidemics. Proc Natl Acad Sci 105: 9835-9840.

Wiznia AA, Crane M, Lambert G, Sansary J, Harris A, Solomon L. 1996. Zidovudine use to reduce perinatal HIV type 1 transmission in an urban medical center. JAMA 275: 1504-1506.

Woodsong C, Masenga G, Rees H, Bekker LG, Ganesh S, Young K, Romano J, Nel A. 2010. Safety and acceptability of vaginal ring as microbicide delivery method in African women. In Microbicides 2010. Pittsburgh.

World Health Organization. 2009. Women and health: Today's evidence, tomorrow's agenda. World Health Organization. http://www.who.int/gender/women_health_report/en/ index.html. 


\section{$\&_{\mathrm{CSH}}^{\infty} \&$ Cold Spring Harbor

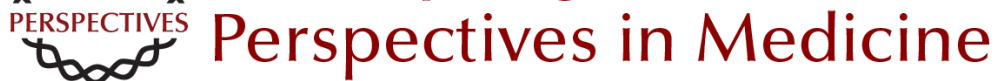

\section{Microbicides: Topical Prevention against HIV}

Robin J. Shattock and Zeda Rosenberg

Cold Spring Harb Perspect Med 2012; doi: 10.1101/cshperspect.a007385 originally published online September 14, 2011

\section{Subject Collection HIV}

HIV Pathogenesis: Dynamics and Genetics of

Viral Populations and Infected Cells John Coffin and Ronald Swanstrom

Human Immunodeficiency Virus Vaccine Trials Robert J. O'Connell, Jerome H. Kim, Lawrence Corey, et al.

HIV Transmission George M. Shaw and Eric Hunter

Novel Cell and Gene Therapies for HIV James A. Hoxie and Carl H. June

Behavioral and Biomedical Combination Strategies for HIV Prevention Linda-Gail Bekker, Chris Beyrer and Thomas C. Quinn

HIV-1 Assembly, Budding, and Maturation Wesley I. Sundquist and Hans-Georg Kräusslich

HIV-1 Assembly, Budding, and Maturation Wesley I. Sundquist and Hans-Georg Kräusslich

Lessons in Nonhuman Primate Models for AIDS Vaccine Research: From Minefields to Milestones Jeffrey D. Lifson and Nancy L. Haigwood
HIV-1 Pathogenesis: The Virus

Ronald Swanstrom and John Coffin

The T-Cell Response to HIV

Bruce Walker and Andrew McMichael

HIV-1 Reverse Transcription Wei-Shau Hu and Stephen H. Hughes

HIV Pathogenesis: The Host A.A. Lackner, Michael M. Lederman and Benigno Rodriguez

HIV: Cell Binding and Entry Craig B. Wilen, John C. Tilton and Robert W. Doms

Innate Immune Control of HIV Mary Carrington and Galit Alter

HIV DNA Integration

Robert Craigie and Frederic D. Bushman

HIV-1-Related Central Nervous System Disease: Current Issues in Pathogenesis, Diagnosis, and Treatment Serena Spudich and Francisco González-Scarano

For additional articles in this collection, see http://perspectivesinmedicine.cshlp.org/cgi/collection/ 